\title{
DAMPAK PERKEMBANGAN BUDAYA MODERN TERHADAP EKSISTENSI BUDAYA LOKAL DI ACEH
}

\author{
Syibran Mulasi \\ Sekolah Tinggi Agama Islam Negeri Teungku Dirundeng Meulaboh \\ syibran@staindirundeng.ac.id \\ $\overline{\text { Abstrak }}$
}

Perkembangan budaya merupakan suatu hal yang tidak mungkin untuk dihindari, dengan perkembangan teknologi informasi perkembangan budaya sudah merambah sampai kemana-mana, bahkan sampai dapat merubah kemurnian budaya lokal dimana budaya baru itu datang termasuk juga pada budaya lokal Aceh sekalipun. Pembahasan ini bertujuan untuk melihat sejauhmana pengaruh budaya modern terhadap eksistensi budaya lokal Aceh yang berkembang dengan perkembangan teknologi informasi. Pembahasan ini dilakukan dengan menelaah teks-teks dan hasil penelitian yang memiliki relevansi dengan tujuan bahasan, penulis mengambil beberapa bentuk perkembangan budaya dan efek pada budaya yang didatanginya. Hasil pembahasan ditemukan bahwa budaya Aceh dengan sengaja telah bergeser dan masyarakat Aceh dengan mudah menerima budaya baru tersebut, dapat terlihat dari bentuk pergaulan muda-mudi, degradasi moral, tingkat perceraian dan perselingkuhan, gaya pergaulan dan komunikasi serta interaksi sosial yang semakin luas. Perubahan dan perkembangan budaya ini harus menjadi proteksi dini bagi seluruh pemangku kebijakan di Aceh untuk melahirkan filterisasi budaya yang membahayakan budaya lokal Aceh dimasa yang akan datang.

Kata kunci : Perkembangan Budaya, budaya modern, dampak budaya lokal Aceh

\begin{abstract}
Abstrak
The development of culture are a thing is not possible to evade, with of development of information technologies the development of culture has expanded until everywhere, even can change purity local culture where new culture came including also in culture local Aceh though. This discussion aims to look at about the influence of modern culture to existence local culture aceh that flourish with of development of information technologies .Discussion this was done in review texts and the results of research having relevance for the purpose subjects, writer take some forms of the development of culture and an effect on cultural took. Discussion result found that cultures aceh by deliberately is shifting and the community aceh by receptive the new culture, are evident in the form of inter communication youth, degradation moral, divorce rates and affair, style inter communication and social interaction s broader. Change and development of this culture has to be early protection for all stakeholders in aceh to bore filterisasi culture to local culture Aceh in which to come.
\end{abstract}

Key word: The development of culture, the modern culture, the impact of the culture Aceh PENDAHULUAN

Perkembangan budaya merupakan

salah satu yang wajar dalam pergeseran dan perkembangan di zaman modern ini, perkembangan ini dinilai hal yang lumrah terjadi dimana saja. Perkemangan budaya modern 
seakan akan tidak lagi menjadi pembatas dan masuk ke pundi pundi kehidupan budaya lokal, masuknya budaya ini identik dengan hal hal baru yang belum pernah ada di masyarakat, bdaya baru tersebut bisa saja bersifat positif dan konstruktif pada perkebangan manusia, namun disisi lain bisa menjadi bumerang negatif terhadap kecaunya kemurnian budaya lokal.

Hancur dan remang remangbnya budaya lokal ini menjadi salah satu permasalahn yng dikhawatirkan oleg banyak pihak, di Aceh misalnya budaya yang tumbuh pada umumnya berjalan sesuai keyakinan masayraakt Aceh pada umumnya, masyarakat Aceh yang identik beragama Islam seakan budaya yang berkembang di tengah tengah masyarakat Aceh tidak terlepas dari budaya Islam. Perkebangan budaya Islam di masyarakat Aceh begitu kental, dimana masyarakatnya sangat menjunjung tinggi nilai nilai adat dan agama Islam.

Masuknya budaya modern atau dalam hal ini budaya baru menjadi sebuah tantangan bagi masyarakat dalam mempertahankan budaya lokal yang telah lama berkembang, satu sisi keberadaan budaya modern ini tidak mampu di elak karena perkembangannya begitu cepat dan tanpa sadar masyarakat Aceh terpaksa berinteraksi dengan budaya baru tersebut, namun di sisi lain kemurnian budaya lokal menjadi tantanagn tersendiri bagi masayrarakat Aceh. Kedatangan budaya baru tersebut dapat membawa pada dua dampak bagi keberlangsungan budaya loka, dampak tersebut dapat terlihat pada dua sisi yaitu perubahan pada segi sosial dan perubahan segi budaya. Bentuk perubahan pada sisi sosial masyarakat terlihat dimana terjadinya perubahan struktur masyarakat lokal dengan beralihnya sektor pekerjaan dari petani atau nelayan ke sektor industri, meningkatnya keinginan untuk berpendidikan tinggi, namun sedangkan perubahan dari segi budaya yaitu terjadinya perkawinan dari dua unsur budaya yang berbeda, perubahan pada penggunaan bahasa, perubahan cara berpakaian dan perubahan perilaku dalam keluarga. (Furqan 2017). ${ }^{1}$

Banyak budaya modern yang terlihat tumbuh dan berkembang di masyarakat misalnya seperti masuknya internet, perubahan tingkah laku masyarakat, gaya pergaulan para remaja serta perubahan nilai-nilai budaya serta adat yang terjadi di masyarakat, dengan budaya teknology baru tersebut seolah olah telah melahirkan ke-praktisan hidup masyarakat yang serba mudah, masyarakat Aceh yang berasal dari budaya tradisional harus menerima kenyataan budaya baru tersebut, serta harus rela masuk dan berkembang dengan budaya-budaya luar tersebut.

Untuk itu, dalam pembahasan ini akan melihat bagaimana pengaruh budaya modern terhadap kemurnian budaya lokal di Aceh, dan bagaimana peran agama dan budaya lokal dalam memproteksi dan memfilter budaya baru tersebut.

\section{PEMBAHASAN}

\section{Pengertian Budaya Modern}

Dalam kamus besar bahasa Indonesi, budaya dapat diartikan sebagai akal fikiran; akal budi, adat istiadat atau sesuatu yang sudah berkembang di masyarakat ataupun suatu yang sudah menjadi kebiasaan nyang sukar untuk dirubah. Budaya biasamya hidup dan berkembang dalam suatu tatanan masyarakat dimana mereka menaati dan menjada bersama sama sebagai dasar pedoman hidup bersama. Ataupun Budaya dapat diartikan sebagai sebua tatanan hidup mansuai yang telah ada dan terbentuk dari setiap kebiasaan berkehidupan. Budaya dapat diartikan juga sebagai perjuangan manuais dalam mengatasi masalah alam dan zaman. $^{2}$

1 M. Furqan, Dampak Wisatawan Asing terhadap Perubahan Sosial Budaya Masyarakat, ETD UNSYIAH online Theses dan Disertation, diakses pada Senin, 2 November 2020 di: https://etd. unsyiah.ac.id/index.php?p=show_detail\&id=33114

$2 \mathrm{Ki}$ Hajar Dewantara, Kebuadayaan, 
Budaya dapat diartikan secara dinamis oleh para ahli, terkadang pengertian budaya juga dipengaruhi oleh waktu dan tempat dimana budaya itu tumbuh. Bagi nelayan misalnya, budaya adalah bagaimana cara menangkap ikan, perayaan syukuran maupun hal lainya yang berkaitan langsung dengan kerja nelayan. Pada zaman mezolitikum misalnya kebudayaan lebih diidentikkan sebagai cara berburu dan hidup secara nomaden(berpindah pindah), begitu pulazaman modern seperti saat ini kebudayaan diartikan sebagai teknologi informasi yang canggih yang berkembang saat ini. ${ }^{3}$

Kebudayaan juga merupakan hasil dari sebuah proses komunikasi anggota masyarakat yang berlangsung secara terus menerus. ${ }^{4}$ Menurut Ki Hajar Dewantara, budaya atau kebudayaan dapat diartikan sebagai buah budi manusia dalam hidup bermasyarakat, sedangkan Koentjaraningrat memaknai kebudayaan sebagai keseluruhan sistem, gagasan, tindakan dan hasil karya manusia dalam rangka kehidupan masyarakat yang dijadikan milik diri manusia dengan cara belajar. ${ }^{5}$ Budaya biasanya berubah rubah sesuai perkebangan zaman, perkembangan teknologi informasi telah ikut menyeret budaya budaya di dunia ini sampai ke pelosok desa. Perkembangan dan perubahan budaya sedikit demi sedikit akan ada pembaharuan, perkembangan budaya di indonesia pada masa kolonial dengan masa

(Yogyakarta: Majlis Luhur Persatuan Teman Siswa, 1994), hal 84.

3 Isma Tantawi, , Dasar Dasar Ilmu Budaya: Deskripsi Kepribadian Bangsa Indonesia, Jakarta: Prenada Media 2019), hal.14.

4AndrikPurwanto, KomunikasiMultikultural, (Surakarta: Universitas Muhammadiyah Surakarta, 2003), hal. 03. hal.13.

5 Isma Tantawi, Dasar Dasar Ilmu Budayahal,,, sekarang sudah bergeser masyarakat dulu yang serbatradisional sedikit demi sedikitbersentuhan dengan budaya modern dan menyesuaikan diri dengan budaya modern tersebut.

Derasnya perkembangan globalisasi dan teknologi informasi telah mengarah pada memudarnya nilai-nilai budaya lokal. Hal ini terlihat bahwa dengan perkemangan tranformasi, telekomunikasi dan teknologi telah mengakibatkan pada keinginan untuk pelestarian budaya lokal yang telah ada semanjak dahulu. Budaya indonesia yang dulkunya ramah tamah, gotong royong dan sopan santun sedikit demi sedikit telah terpengaruh dengan budaya barat seperti pergaulan bebas. ${ }^{6}$ Berbicara mengenai perkembangan budaya, dari tradisional menjadi maju dan modern tentu dipengaruhi oleh pergerakan alam dan teknologi, melalui teknologi masyarakat dapat lebih leluasa menikmati perkembangan dan mengenal budaya yang lebih luar, ketertarikan akan budaya luar tanpa filterisasi budaya lokal yang telah mengakar di masyarakat patut menjadi pertian, karena perkembangan dan pengenalan budaya baru tersebut terkadang tidak sesuai dengan internalisasi budaya lokal yang telah terbentuk secara turun temurun, di Aceh misalnya berkembangnya teknologi telah merubah beberapa sendi sendi kehidupan budaya yang telah ada, masyarakat yang dulunya menjunjung tinggi nilai nilai agama akan terkikis bergeser ke budaya baru yang dinikmati melalui teknologi informasi.

Suatu hal yang sangat tabu bagi masyarakat Aceh apabila berbuat suatu

6 Nuhaidah, M, Insya Musa, Dampak Pengaruh Globalisasi bagi Kehidupan Bangsa Indonesia, Jurnal Pesona Dasar, Vol.3 No.3 April 2015. Jurnal PGSD Universitas Syiah Kuala, hal. 10. 
kesalahan yang bertentangan dengan agama, pergaulan bebas muda mudi misalnya merupakan suatu yang tabu bagi masyarakat Aceh, menghormati guru menjadi suatu yang sakral dijalankan oleh masyarakat tempoe dulu, atau rasa soasial yang tinggi terlah bergeser pada budaya individualis yang tidak mau tau kehidupan masyarakat lain. Ini lah yang menjadi hal negatif dari perkembangan budaya baru apabila tidak dibentengi oleh pengetahuan agama dan budaya yang telah ada.

Budaya modern atau budaya baru dapat diartikan sebagia sebuah tatanan kehidupan baharu akibat perkembangan teknologi informasi yang belum pernah ada yang datang dalam suatu masyarakat yang telah merasuk dan merubah budaya lokal yang telah ada sehingga dapat berdampak pada kelestarian budaya yang telah ada. Masuknya budaya baru dalam sebuah wilayah dapat berdampak positif bahkan juga negatif dalam menjaga kemurnian budaya yang telah menjadi tatanan berkehidupan dalam suatu wilayah.

\section{Aceh dan Perkebangan Budaya Modern}

Aceh merupakan suatu wilayah di nusantara yang telah berkembang dan berubah dari berbagai sektor dan sala satunya di segi budaya, sebagaimana yangdiketahuisebelumnya Aceh merupakan sebuah wilayah yang juga oernah berkembang dan menganut budaya dari hindu dan budha sebelum masuknya Islam ke nusantara, Snouck Hurgronje dalam sebuah catatan menyebutkan, sebelum Islam masuk ke Aceh, pengaruh hindu dan budha sudah terlebih dahulu mempengaruhi masyarakat, baik secara langsung maupun tidak langsung. Snouck menunjukkan fakta dari kesamaan bahasa dan budaya antara Aceh dan India ${ }^{7}$ ia berasumsi bahwa pengaruh perkembangan budaya hindu dan budha di Aceh akibat dibawakan oleh para pedagang dari negara indian (kleng), baginya Aceh tidak hanya kedatangan pedagang dari muslim saja tetapi orang-orang cetti dan hindu pun sudah sejak lama berdagang di Aceh.

Perubahan budaya Aceh yang dipengaruhi hindu budha kemudian diintegrasikan menjadi budaya yang bernuansa Islami oleh sultan Ali Mughayat Syah pada abad ke-15. ${ }^{8}$ saat masa itu Aceh melalui keajaan Islam telah menjalankan Islam dengan sangat baik sehingga mempresentasikan budaya Aceh yang Islami walaupun beberapa budaya lokal yang telah ada masih ada di Aceh seperti budaya Tepung Tawar (peusijuk), boh gaca (pakai inai pada pengantin) perayaan tulak bala dan beberbagai budaya lokal yang pernah berkembang masih tetap ada walaupun saat ini sudah berkurang terutama yang bertentang dengan budaya atau ajaran Islam

Perkembangan dan masuknya budaya modern dalam masyarakat Aceh dapat membawa pada dua dampak, yaitu dampak negatif pada hilangnya kemurnian budaya lokal Aceh yang sudah lama berafiliasi dengan ajaran Islam telah lama menjadi tatanan hidup masyarakat Aceh, juga akan memberikan dampak positif terhadap perkemganan dan peningkatan kemajuan masyarakat Aceh. Dua dampak tersebut membuka perhatian serius dalam menciptakan sebuah filterisasi untuk menjaga kemurnian budaya yang patut dijaga yang telah ada.

7 Snouck Hurgronje. Terj. Ng. Singarimbun, Aceh Dimata Kolonial, (Jakarta: Yayasan Soko Guru) hal 20.

8 Kamaruzzaman Bustaman Ahmad, Acehnology (Banda Aceh: Bandar Publishing, 2012), hal 121-132 
Perkembangan budaya modern dari perkembangan teknologi informasi memang tdak bisa dihindari, dimana perkembangan budaya baru itu tentu akan berakibat pada bercampurnya dengan budaya-budaya yang telah ada, sebagai contoh dari perkembangan budaya, Aceh yang dulunya sangat tabu perempuan berboncengan dengan laki-laki yang bukan muhrim dalam sebuah kereta lama kelamaan sudah menjadi terbiasa akibat perkembangan budaya, contoh lain suorang wanita (istri orang) tidak terbiasa duduk ngopi semeja dengan lelaki yang bukan suaminya sampai pada kenyataan perubahan yang sudah dianggap lumrah disebabkan karena kebutuhan pekerjaan, dampak negatif lainnya tingginya angka perceraian. ${ }^{9}$ dan perselingkuhan yang terjadi di Aceh saat ini juga diakibatkan oleh pergeseran budaya maju dimana tingkat filterisasi diri yang belum begitu kuat sehingga menerima budaya baru yang berkembang tersebut dengan melupakan identitas diri dan budaya lokal yang telah ada.

Jika melihat lebih jauh, perkembangan budaya modern sedikitnya akan membawa beberapa dampak negatif terhadap keberlangsungan budaya lokal, sebagaimana yang diungkapkan oleh Nursid, S dan Wihardit, K (2010) dalam bukunya diantaranya:

a. Penyalahgunaan media teknologi sebagai sarana pencarian hal-hal yang tidak ada hubungan dengan ilmu pengetahuan.

b. Timbulnya praktek-praktek curang

9 Koran Onlien Dialeksis, Tiap tahunnya, Angka perceraian di Aceh bertambah 300-35-per tahun, Jum'at, 10 Juli 2020. Diakses pada Senin, 2 November 2020, dari https://dialeksis.com/Aceh/tiaptahunnya-angka-perceraian-di-Aceh-bertambah300-350-per-tahun/ dalam dunia kerja seperti korupsi, kolusi dan nepotisme.

c. Sekulerisasi, merupakan sebuah proses pemisahan institusi-institusi dan simbol-religius.

d. Munculnya liberalisme yaitu suatu sikap ideologi modern, karena ia muncul bersamaan dengan modernisasi dan segala pertentangan ideologi dalam masyarakatt modern tak lain daripada pertentangan dengan liberalisme.

Munculnya sikap dan isu pluralisme dimana lahir sebuah pandangan yang beroperasi di dalam kebudayaan dalam bentuk sikapsikap yang menerima kemajemukan orientasiorientasi nilai di dalam masyarakat moder. The fact of plurality yaitu suatu kenyataan bahwa jika sebuah masyarakat mengalami modernisasi, maka masyarakat itu mengalami pluralisme nilai dalam dirinya. (Nursid 2010) ${ }^{10}$

Kalau diamati dari penjelasan diatas bahwa dampak negatif yang timbul dari perkembangan budaya baru akan menganggu kemurnian budaya lokal, Aceh dan Islam merupakan suatu paduan budaya yang telah mengakar dalam kehidupan masyarakat Aceh, munculnya budaya-budaya yang masuk melalui perkembangan teknologi ini akan membuka cakrawala mata masyarakat untuk menikmati budaya luar yang belum tentu sejalan dengan budaya Aceh yang notabene Islam.

Budaya masyarakat Aceh yang Islami secara keseluruhan memang berbeda dengan pandangan hidup orang barat kapitalis, sebagaimana diungkapkan oleh Francis 10 Nursid dan Wihardit, Perpektif Global, (Jakarta: Universitas Terbuka, 2010), hal.12 
Fukuyama dalam bukunya The End of History, and the Last Man, mengakui bahwa dunia barat kini Posmodern dengan menganut prinsip "free market" kapitalisme dan liberalisame yang merupakan babak akhir dari sejarah manusia (the end of history), artinya paham liberalisme merupakan alternatif terakhir bagi umat manusia, paham apapun yang tidak mengakomodir ciri-ciri ini akan tersingkir dari proses evolusi menuju kesempurnaan sejarah atau tertinggal jauh di belakang. ${ }^{11}$ Aceh yang sudah menganut budaya Islam, dengan munculnya budaya baru yang berbau kapitalisme tentu menjadi sebuah bahaya yang lama kelamaan akan dilindas, budaya barat yang serba praktis akan lebih mudah masuk dan diterima oleh kaum muda saat ini, kebanggaan pada budaya baru dengan tanpa sadar kaum muda akan hilang identitas diri sebagai orang Aceh. Hal ini terlihat dari bentuk pakaian, tatakrama, pergaulan bebas, pergeseran budaya yang sosialis ke individualis, ketaatan terhadap agama Islam dan lainnya akan dijumpai pada masyarakat Aceh di masa yang akan datang.

\section{Peran Agama di Era Budaya Modern Aceh}

Agama merupakan suatu tatanan hidup yang dibawakan Rasullulalh SAW yang diperuntukan untuk seluruh umat manusia (hudan linnasi), ajaran agama samawi ini telah berkembang dan berintegrasi langsung dengan budaya lokal dimanapun dia berkembang tidak terkecualikan di nusantara maupun Aceh itu sendiru, penyesuaian dan maskmya budaya

11 Hamid Fahmy Zarkasyi, Worldview Islam dan Kapitalisme Barat, Jurnal taqafah, vol.9, no.i, April 2013. Diakses Senin, 2 November 2020 di: https:// ejournal.unida.gontor.ac.id/index.php/tsaqafah/ article/view/36
Islam dalam tatanakan kehidupam masyarakat Aceh bisa dikatakan dengan cara yang sangat lunak dan masyarakat Aceh dengan perlahan dan mudah menerima budaya dan ajaran Islam yang nantinya dijadikan norma serta pediman hidup di masyarakat, dalam memperkuat Islam para ulama dahulu telah mendirikan banyak lembaga pendidikan Islam, mulai pendidikan dasar, menangah sampai pendidikan tinggi telah pernahada di Aceh. Hal ini mendapat dukungan langsung dari kerajaan Aceh Darussalam, sebagaimana tiga unsur kepemimpinan Aceh masa kerajaan Aceh Darussalam dimana ulama ditempatkan sebagai mufti kerajaan yang dijadikan rujukan setiap kebijakan yang akan dijalankan Sultan.

Perkembangan agama Islam dan budaya Islami terus berkembang sampai melahirkan banyak ulama yang diakui dunia seperti Hamzah Alfansuri, Abdurrauf As-Singkilie, Nurrruddin ar-Raniry, hal ini membuktikan bahwa perhatian sultan terhadap agama Islam sangatlah tinggi, disamping itu juga terlihat dari berbagai persyaratan menjadi pemimpin di Aceh yang tidak terlepas dari syarat-syarat yang ditetapkan tentu merujuk pada ajaran agama Islam.

Perkebangan budaya dan agama di Aceh bisa dikatakan bagaiman dua sisi mata uang yang tidak mungkin dipisahkan, yaitu antara satu dan sisi yang lain saling berkaitan memberikan peran, sebagai contoh pelestarian tari sama, dimana dalam salah satu kesenian Aceh tersebut ada nilai-nilai agama Islam yang 
menjadi rujukannya, disamping itu juga sistem adat di Aceh tentu akan mengikutsertakan agama yang dianut masyarakat, seperti tabi'at peumulia Jamee (memuliakan tamu), budaya saleum (salam), budaya menghormati guru dan orangtua yang jalas tergambarkan dalam hadih maja "poma ngoen ayah keu lhee ngoen guree, ureung nyan ban lhee meu bek ta dhoet-dhoet, menyo na salah meu ah talake, peumiyuep ulee ta coem bak teu oet" (ibunda dengan ayah yang ketiga guru, mereka bertiga jangan sekali-kali dimarahi, kalau ada suatu kesalahan/kekhilafan mohonlah maaf, rendahkan kepala lakukan sembah sujud", keberadaan Islam sangat dirasakan di Aceh, dan orang Aceh sejak zaman dahulu sangat unik dalam mengajarkan agama pada masyarakat, walaupun masayarakatnya notabene buta huruf namun memasukkan nilainilai agama melalui sya'ir-sya'ir dan ragam kesenian budaya, maka terkadang jelas terlihat nilai-nilai budaya dan agama selalu hadir dalam pertunjukan kesenian di Aceh.

Keterkaitan budaya dan agama di Aceh juga sangat kental ditemukan dalam kuatnya orang Aceh dalam mempertahankan agama, hikayat perang sabil misalnya, mampu menggugah hati orang Aceh dalam mempertahankan wilayahnya dengan sebutan perang syahid (hudep saree matee syahid), pihak belanda menderita banyak saat itu, bahkan Jendral Kohler gugur beserta 8 opsir dan sejumlah prajurit. (Abdullah 2000, 242) keterkaitan agama sangat kental dan merupakan salah satu kekuatan yang tidak terbendung di
Aceh semenjak dahulu.

Islam dan Aceh memang menjadi sebuat kombinasi yang tidak mungkin dipisahkan walaupun nilai-nilai budaya non-Islam juga tidak bisa dihindari, karena sifat Islam dan Aceh lebih mudah menerima budaya-budaya yang berkembang, walaupun terkadang lolos proteksi agama dalam menerima mentah mentah budaya baru itu, sebagai bukti loss control agama masyarakat dalam menikmati budaya baru dapat dilihat dari pesatnya pergeseran budaya yang terjadi di masyarakat, misalnya persepsi masyarakat terhadap pesantren, yang dulunya pesantren tradisional menjadi primadona lama kelamaan dapat tersaingi dengan tumbuh dan berkembangnya pesantren moderen di Aceh. Pergeseran ini terlihat dari berkembangnya budaya global yang dapat dinikmati langsung melalui teknologi informasi oleh pemudapemudi di Aceh.

Agar budaya dan agama di Aceh tetap terjaga kemurnianya selaiknya peran agama perlu ditingkatkan di Aceh, perlunya modifikasi sistem pendidikan Islam yang dapat diperlakukan sejajar dengan pendidikan umum lainnya. Pengintegrasian kembali lembaga pendidikan menjadi hal yang wajar, karena dikotomi pendidikan telah melahirkan persepsi seolah-olah pendidikan Islam hanyalah sebatas yang bersifat ibadah mahdhah atau yang bersifat akhirat, sedangkan permasalahan duniawi ditangani dan lahir dari pendidikan umum. Padahal jelas terlihat bahwa dalam pemahaman agama dituntun umatnya bahwa Allah SWT 
sang pemilik alam semester ini merupakan suatu Dzat yang maha Mengetahui, sumber dari segala ilmu pengetahuan yang tersebar di alam ini, jadi seyogyanya dikotomi pendidikan merupakan rancangan barat untuk membuat seolah Islam hanya sebatas pada pengetahuan yang bersifat $u k h r a w i$ saja.

\section{1,27 cmDampak Perkembangan Budaya}

\section{Modern di Aceh}

Sebagai halnya sebuah tatanan kehidupan yang cendrung selalu bergeser dan berubah-rubah, begitulah juga dengan budaya. Perkebambangan budaya luar saat ini telah masuk sampai ke setiap pelosok kehidupan umat manusia, perkembangan tersebut ditandai dengan bergernya cara fikir masyarakat, gaya hidup serta cara komunikasi yang berbeda dari masa ke masa, di Aceh misalnya, masuknya budaya luar melalui berbagai media teknologi telah merubah tatanan kehidupan masyarakat Aceh yang tradisional menjadi gaya modern.

Bisa diamati misalnya perubahan bentuk warung kopi (warong kupi), di Aceh warung kopi memang bukan hal langka untuk di cari, karena disamping tempat orang menikmati kopi juga warung telah dijadikan sebagai tempat untuk keperluan lainnya, mulai mencari informasi, berbisnis, tempat pertemuan bahkan tempat menyelesaikan masalah kecil kecilan juga warung menjadi tempatnya. Warung kopi tradisional di kampung (pelosok desa) Aceh yang hanya memiliki fasilitas sederhana misalnya hanya sebagai wadah kaum lelaki tempat melakukan pertemuan, tempat menonton acara TV atau siaran pertandingan bola, atau menonton film-film, warung kopi dulu memang lebih dominan di huni kaum adam, karena tempatnya lelaki memang di warung kopi, namun saat ini perubahan itu datang searah berkembangnya teknologi informasi, warkop yang dulunya hanya dihuni kaum adam saat ini wanita pun tidak menjadi tabu lagi berada di warung kopi, hal ini juga dipengarhi faktor berubahnya stail warung dari warung dengan fasilitas klasik menjadi modern, hampir semua warkop yang dihuni remaja itu tersedianya fasilitas wifi/jaringan internet, dan kebutuhan pun ikut berkembang mulai dari bisnis, pertemuan para elit sampai remaja menggunakan wifi warkop sebagai media belajar dan mencari informasi.

Perubahan lain juga dapat dijumpai pada acara pesta $\left(\right.$ khanduri $^{12}$,yang secara tatalaksananya juga sudah berubah, dahulu semua orang kampung dengan suka rela kompak menyelesaikan sebuah acara di rumah warga, semuanya dikerjakan dari panitia-panitia yang telah dibentuk, namun dengan perkembangan hari ini ditambah kesibukan bergeser ke yang lebih praktis, tempat pesta tinggal disewakan

12 Sistem acara (pesta/orang meninggal) khanduri di Aceh tempo dulu sangat mengedepankan kekompakan kerja masyarakat, pemilik rumah hanya menyediakan tempat dan segala kebutuhan untuk acara, namun masyarakat dalam desa tersebut yang mengerjakan semuanya kebutuhan yang diperlukan, mulai buat tempat penerimaan tamu (seung), memasak, menyediakan hidangan saat acara sampai pembubaran panitia laksana khanduri yang diangkat dari orang-orang yang dipertuakan di desa sampai unsur pemuda, hal itu sama-sama dikerjakan dengan suka rela. 
pada pemilikmnya, makanan juga tinggal di charter dari catering, dan lain sebagainya.

Perubahan interaksi sosial dan perkembangan kebudayaan memang senantiasa mengalami perubahan sesuai dengan tingkat kebutuhan manusia, sebagian dari perubahan tersebut terjadi dengan begitu cepat dan sebagian lagi mungkin terasa lambat. Perubahan kebudayaan dapat terjadi secara tidak sengaja seperti dalam kejadian tertimpa musibah bencana alam, seperti banjir, gempa dan Tsunami, kebakaran dan lain sebagainya yang memaksa masyarakat untuk berpindah, perubahan dan mobilitas masyarakat inilah terkadang menjadi pemicu terjadinya pembaharuan dan pembaharuan kebiasaan hidup dan pola interaksi sosial. ${ }^{13}$ (Yoga 2018, 34)

Perubahan individu terkedang juga disebabkan oleh konsumsi informasi yang mengena dengan pendapatnya, terkadang seseorang akan berusaha mencari suatu pengetahuan yang diinginkan, maka untuk memperkuat pendapat dan keinginannya terkadang masuk lebih jauh menembus budaya-budaya yang belum pernah dikenali sekalipun. Maka perkembangan budaya terkadang berpengaruh pada sikap selective perception dimana seorang individu secara sadar akan mencari media yang mendorong kecenderungan dirinya. Kecenderungan tersebut bisa memperkuat keyakinan diri, atau

13 Yoga, Salman S. "Perubahan Sosial BUdaya MAsyarakat Indonesia dan Perkembangan Teknologi Informasi." Al Bayan Vol.4 No.1 Januari-Juni 2018, 2018: 34 . dengan kata lain selecive perception merupakan kecenderungan seseorang hanya untuk mengingat pesan yang sesuai dengan pendapat dan kebutuhan dirinya sendiri. ${ }^{14}$

Dalam sebuah catatan yang pernah dimuat di media serambi indonesia menyatakan bahwa:

Alam pemikiran rakyat Aceh yang notabene Islam saat ini sudah tidak lagi murni berangkat dari ajaran Islam(al-Qur'an dan Hadits) tetapi sudah bercampur denga dialektika keduanya, bahkan kata dia lebih memprihatinkan lagi hampir semua produk pemikiran, mulai terkontaminasi atau berada di bawah skenario barat yang notabene suka melakukan eksperimen tentang pemikiran. Akibatnya, muncul pertanyaan, apakah tidak mungkin kita generasi Aceh sekarang menjadi percobaan eksperimen barat? Pengaruh ini menyerap tidak hanya pada grass rootlevel, tapi juga menggejala pada middle dan elit level. Untuk itu, wujud dari pengaruh ini tercermin dari sikap hidup sehari hari, cara berbicara, berpakaian bahkan dalam mengambil keputusan. ${ }^{15}$

Perkembangan budaya memang tidak mungkin bisa dihindari, Aceh yang telah memasukkan nilai-nilai Islam dalam pelestarian budayanya ikut terdampat dari budaya modern yang masuk melalui teknologi informasi, dari pergeseran beberapa budaya yang berkembang

14 Nurdin, Komunikasi Masa, (Malang: Cerpur 2003), hal. 214.

15 Serambi Indonesi. Serambi Indonesia. September 25, 2011. https://aceh.tribunnews. com/2011/09/25/pengaruh-barat-terhadap-aceh (accessed November 03, 2020) 
saat ini dapat dilihat merupakan sebuah ancaman dalam menjaga kemurnian budaya lokal, Aceh perlu melahirkan kurikulum dan lembaga warisan budaya yang dapat menjadi bahan edukasi pada masyarakat.

Disamping itu juga perlunya peningkatan pemahaman dasar agama dan budaya yang kuat pada para remaja, perkuat keluarga dalam menjalankan fungsi Islam dalam mendidik anak, tingkatkan peran pemerintah dan ulama dalam mewacanakan regulasi yang mengarah pada menjaga kelestarian agama dan budaya, dan usaha-udaha lainnya yang mengarah pada kuatnya nilai agama dalam tatanan masyarakat di Aceh.

\section{KESIMPULAN}

Budaya sama halnya dengan manusia, dia bersifat statis berubah-rubah, perubahan budaya tentu di latari oleh beragam faktor, baik faktor pendidikan yang dilakukan dengan sengaja, faktor konsumsi informasi serta faktor lainnya yang terkontaminasi dengan budaya lokal.

Aceh yang budayanya Islam dengan sifat dasarnya sangat menerima budaya baru, namun Islam memberikan filterisasi dalam memproteksi budaya-budaya yang bertentangan dengan nilai-nilai syar'I, Islam yang memiliki proteksi terhadap budaya luar, juga seharusnya Aceh yang harus mempersiapkan proteksi budaya dan adat-istiadat dari budaya yang berkembang yang dapat merusak kemurnian budaya, perkembangan memang tidak dapat dipungkiri, namun yang bersifat merusak nilai ketimuran itu yang harus menjadi sebuah kekhawatiran.
Menghadapi perkembangan budaya baru ini Aceh perlu mengupayakan beberapa usaha, diantaranya; perkuat keluarga muslim dengan bekal agama yang susuai dengan al-Qur'an dan Hadits, menciptakan sietem pendidikan yang berorientasi pendidikan religius dan culture Aceh, perlu adanya filterisasi pemerintah terhadap budaya modern, pemerintah harus proaktif dan serius peduli terhadap degradasi moral yang sedang terjadi, serta perkuat sistem kemasyarakat Aceh yang lebih sosialis dan saling menjaga.

\section{DAFTAR PUSTAKA}

Abdullah, Imran T. "Ulama dan Hikayat Perang Sabil dalam perang Belanda di Aceh ." Humaniora, 2000.

Furqan, M. "Dampak Wisatawan Asing tehadap perubahan sosial Budaya Masyarakat, ETD UNSYIAH." Theses and Disertation UTD UNSYIAH. Juli 20, 2017. https:// etd.unsyiah.ac.id/index.php? $\mathrm{p}=$ show detail\&id=33114 (accessed November 02, 2020).

Serambi Indonesi. Serambi Indonesia. September 25, 2011. https://aceh. tribunnews.com/2011/09/25/pengaruhbarat-terhadap-aceh (accessed November 03, 2020).

Nursid, Wihardit. Perspektif Global. Jakarta: Universitas Terbuka, 2010.

Yoga, Salman S. "Perubahan Sosial BUdaya MAsyarakat Indonesia dan Perkembangan Teknologi Informasi." Al Bayan Vol.4 No.1 Januari-Juni 2018, 2018: 34.

M. Furqan, Dampak Wisatawan Asing terhadap Perubahan Sosial Budaya Masyarakat, ETD UNSYIAH online Theses dan Disertation, diakses pada 
Senin, 2 November 2020 di: https:// Koran Onlien Dialeksis, Tiap tahunnya, Angka etd.unsyiah.ac.id/index.php? $\mathrm{p}=$ show perceraian di Aceh bertambah 300-35-per detail\&id=33114 tahun, Jum 'at, 10 Juli 2020. Diakses pada

Ki Hajar Dewantara, Kebuadayaan, Yogyakarta: Senin, 2 November 2020, dari https:// Majlis Luhur Persatuan Teman Siswa, 1994.

Isma Tantawi, , Dasar Dasar Ilmu Budaya: dialeksis.com/Aceh/tiap-tahunnyaangka-perceraian-di-Aceh-bertambah300-350-per-tahun/

Deskripsi Kepribadian Bangsa Indonesia, Nursid dan Wihardit, Perpektif Global, Jakarta: Jakarta: Prenada Media 2019. Universitas Terbuka, 2010.

Andrik Purwanto, Komunikasi Multikultural, Hamid Fahmy Zarkasyi, Worldview Islam Surakarta: Universitas Muhammadiyah dan Kapitalisme Barat, Jurnal taqafah, Surakarta, 2003.

Nuhaidah, M, Insya Musa, Dampak Pengaruh vol.9,no.i, April 2013. Diakses Senin, Globalisasi bagi Kehidupan Bangsa 2 November 2020 di: https://ejournal. unida.gontor.ac.id/index.php/tsaqafah/ Indonesia, Jurnal Pesona Dasar, Vol.3 article/view/36

No.3 April 2015. Jurnal PGSD Universitas Syiah Kuala.

Nurdin, Komunikasi Masa, Malang: Cerpur 2003.

Snouck Hurgronje. Terj. Ng. Singarimbun,

Aceh Dimata Kolonial, Jakarta: Yayasan Soko Guru.

Kamaruzzaman Bustaman Ahmad, Acehnology Banda Aceh: Bandar Publishing, 2012. 